\title{
Effects of dietary inclusion of commercial toxin binders and prebiotics on performance and immune responses of broiler chicks fed aflatoxin-contaminated diets
}

\author{
D. Mohseni Soltani ${ }^{1}$, H. Aghdam Shahryar ${ }^{1 \#}$, S.A. Hosseini ${ }^{2}$, Y. Ebrahimnezhad ${ }^{1}$ \\ \& A. Aghashahi ${ }^{2}$ \\ ${ }^{1}$ Department of Animal Science, Shabestar Branch, Islamic Azad University, Shabestar, Iran \\ ${ }^{2}$ Agricultural Research, Education and Extension Organization (AREEO)
}

(Received 26 January 2018; Accepted 1 August 2018; First published online 22 April 2019)

\author{
Copyright resides with the authors in terms of the Creative Commons Attribution 4.0 South African License. \\ See: http://creativecommons.org/licenses/by/4.0/za \\ Condition of use: The user may copy, distribute, transmit and adapt the work, but must recognize the authors and \\ the South African Journal of Animal Science
}

\begin{abstract}
This study aimed to evaluate the efficiency of the dietary inclusion of commercial toxin binders (CTs) and prebiotics on growth performance, immune responses, intestinal morphology and blood variables of broiler chicks fed with aflatoxin and non-aflatoxin-contaminated diets. Six hundred one-day-old male Ross 308 broiler chicks, initial weight of $42 \pm 3 \mathrm{~g}$, were used in 10 treatments with six replications ( $\mathrm{n}=10$ birds). ASRI1 and ASRI2 commercial toxin binders and lactose prebiotic were included in their diets. Experimental diets included: 1) basal diet without aflatoxin and additives (NC); 2) basal diet containing aflatoxin (PC); 3) NC diet containing ARSI1; 4) NC diet containing ARSI2; 5) NC diet containing prebiotics; 6) PC diet containing ARSI1; 7) PC diet containing ARSI2; 8) PC diet containing prebiotics; 9) PC diet containing ARSI1+prebiotics; and 10) PC diet containing ARSI2+prebiotics. Growth performance, humoral and cellular immune responses, jejunal morphology and some blood variables were assessed. Results showed that broiler chicks fed with a PC diet showed a higher feed conversion ratio and lower body weight in the grower and finisher periods. Broiler chicks fed with PC diets showed lower immunoglobulin G and $M$ and also cellular immunities compared to the NC diet. The PC group also showed lower values for villus length, villus width and crypt depth, and higher values for liver enzyme activities compared to the PC diet. However, dietary inclusion of prebiotics and CTs, in single and combined form, improved growth performance in grower and finisher periods, cellular and humoral immunities, intestinal morphology and the serum concentration of triglycerides, cholesterol, glucose and liver enzyme activities of broiler chicks fed with aflatoxin.
\end{abstract}

Keywords: Aflatoxin, ASRI1 toxin binder, broiler chicks, growth performance, humoral immunity

\#Correspondingauthor: ha shahryar@yahoo.com

\section{Introduction}

Mycotoxins are known as fungi toxic metabolites and fungi found in agricultural products (Abdallah et al., 2015; Bhatti et al., 2016). Mycotoxins have adverse effects on animal and human health (Khan et al., 2017). This has been reported for more than 500 types of mycotoxins (Nematiet al., 2015). Aflatoxin, ochratoxin, fumonisin and zearalenoneare the most important contaminants in bird diets (Binder et al., 2007; Saleemi et al., 2017). Studies have also reported that the gut system is adversely affected by pathogens and other contaminants when broiler chicks are fed low-quality feedstuffs (Agboola et al., 2014). However, the primary function of the gut ecosystem is the digestion of feed, and it acts as a defense against contaminants which can influence growth and immunity in animals (El Miniawy et al., 2014; Marin \&Taranu, 2015). It has been reported as a $21 \%$ reduction in body weight of broilers fed with $300 \mu \mathrm{g} / \mathrm{kg}$ AFB1 in their diet (Raju \& Devegowda, 2002). It has been shown that birds receiving mycotoxins have lower antibody titers (Girish et al., 2008; Khan et al., 2014). Studies have also shown that aflatoxin-contaminated diets may cause biochemical and physiological damage to the liver (Gowda et al., 2008; Rezaret al., 2007). In addition, aflatoxin in the diet alters the level of the serum biochemical parameters in animals, indicating that these parameters can be considered a major cause of aflatoxicosis (Basmacioglu et al., 2005). Pelicano et al. (2005) have reported that pathogens disrupt the normal microflora and intestinal epithelium, which not only 
cause malfunction in the ability to digest and absorb nutrients but also reduce the villus height in the small intestine. Appropriate nutritional strategies could alleviate the adverse effects of mycotoxins on the performance and immunity of birds.

Gibson \& Roberfroid (1995) have defined prebiotics as a non-digestible food ingredient which can have beneficial effects by increasing the growth and/or activity of one or more intestinal bacteria in the colon. It is suggested that prebiotics should not be hydrolyzed or absorbed in the digestive system, and must enhance selective substrate absorption and promote growth of commensal bacteria; it should alter gut microbiota to improve the luminal or systemic effects on the animal (Ribeiro et al., 2007). In other words, some carbohydrates which may be fermented by intestinal microorganisms are classified as prebiotics (Bauer et al., 2006) such as resistant starch and non-digestible oligosaccharides. Mannanoligosaccharides can prevent pathogen adherence and block colonization by allowing bacteria to bind with the compound molecules (Ribeiro et al., 2007). Prebiotics can reduce the number of clostridia and increase colonization resistance to pathogens (Ohimain \& Ofongo, 2012). Studies have also reported that prebiotics can increase the digestibility and performance parameters by providing optimum conditions for the growth of beneficial bacteria (Steiner, 2006). Toxin binders are extensively applied in diets because of their montmorillonite content; bentonites swell and form thixotropic gels (Duarte \& Smith, 2005). Eralsan et al. (2005) have indicated the effectiveness of sodium bentonite in minimizing the damage caused by aflatoxins (1 mg/kg) in 45-day-old broiler chickens. Toxin binders are derived from the cell wall of yeast, which is porous on the surface and can trap mycotoxins (Banlunara et al., 2005). Toxin binders can boost antioxidant activity via ionic, hydrogen bond and hydrophobic interactions (Huwig et al., 2001). Gao et al. (2008) stated that the inclusion of yeast in the diet significantly enhances the digestibility of calcium and phosphorus and the intestinal mucosal morphology in broiler chicks. To date, no research has been conducted to evaluate the effects of prebiotics on performance, immunity responses and blood variables in broiler chicks fed feedstuffs contaminated with aflatoxin. However, prebiotics block the epithelial barrier response which causes cytotoxicity by intra-epithelial lymphocytes (Mundi et al., 2017). It also increases the microbial population which may help alleviate the adverse effects of aflatoxins. Considering the adverse effects of aflatoxins on growth performance, immunity and intestine morphology and the positive effects of prebiotics and toxin binders on growth and immunity, this study aimed to investigate the efficiency of the combined dietary inclusion of commercial toxin binders and their effect on the yeast cell wall, and the impact of lactose prebiotics on growth performance immune responses, intestinal morphology and certain blood biochemical variables of broiler chicks fed with aflatoxin and non-aflatoxin-contaminated feedstuffs.

\section{Materials and Methods}

All the procedures followed, were approved by the Islamic Azad University (Shabestar-Iran) Care and Use Committee (SU. 05/December 2016). Six hundred one-day-old male Ross 308 broiler chicks, initial weight $42 \pm 3 \mathrm{~g}$, were tested. Broiler chicks were raised in pens from 1 to 42 days of age. Lighting programme was 23L : 1D during the experimental period, and birds also had unlimited access to feed and water. Birds were randomly allocated to 10 treatments with six replications, with 10 broiler chicks in each replicate. The diets were formulated in three phases, including starter (0 - 10 days), grower (11 - 24 days) and finisher (25 - 42 days). Birds were fed the contaminated and uncontaminated diets containing ASRI1 and ASRI2 commercial toxin binders and prebiotics. Experimental treatments were: 1) birds fed a basal diet without aflatoxin and additive (NC); 2) birds fed a basal diet containing aflatoxin (PC); 3) birds fed an NC diet containing ARSI1 (NC+ASRI1); 4) birds fed an NC diet containing ARSI2 (NC+ASRI2); 5) birds fed an NC diet containing prebiotics (NC+Pre); 6) birds fed a PC diet containing ARSI1 (PC+ASRI1); 7 ) birds fed a PC diet containing ARSI2 (PC+ASRI2); 8) birds fed a PC diet containing prebiotics (PC+Pre); 9) birds fed a PC diet containing prebiotics+ARSI1 (PC+Pre+ASRI1); and 10) birds fed a PC diet containing prebiotics+ARSI2 (PC+Pre+ASRI1). Multiple function toxin binders produced by the Animal Science Research Institute were used which contained bentonite, yeast wall, organic acid and vitamins. ASRI 1 and ASRI 2 toxin binders had respectively $40 \%$ and $60 \%$ bentonite-based yeast wall. Lactose was used as a prebiotic. All the diets were prepared in mash form and formulated on the basis of the catalogue, Ross 308 (Ross 308 Broiler, 2007) (Table 1). Each of the toxin binders was included in diet at a rate of $3 \mathrm{~kg} / \mathrm{ton}$ and a prebiotic was also included at level $1 \mathrm{~kg} / \mathrm{ton}$. Crude protein was analyzed as recommended by AOAC (2005). In grower and finisher periods, the AFB1 concentration was $>1.5$ and $0.2 \mathrm{mg} / \mathrm{kg}$ feed in $\mathrm{PC}$ and NC groups, respectively.

Feeds were contaminated with aflatoxin B1 (AFB1) based on the methods described by Khan et al. (2017). Briefly, the feed was moistened with water to enhance the absorption of the aflatoxin and 15-day-old cultures of Aspergillus parasiticus PTCC-5286 which had been grown on potato dextrose agar slants and mixed in thoroughly. It was preserved and stored in bags for 18 days at ambient temperature in order to increase the production of mycotoxins. AFB1 was added from 11 days of age. 
Table1 The experimental diet used in starter, grower and finisher period of chickens

\begin{tabular}{lccc}
\hline Ingredients & Starter (0-10 d) & Grower (11-24 d) & Finisher (25-42 d) \\
\hline Corn grain & 51.8 & 58.2 & 62.2 \\
Soybean meal (44\% CP) & 38.3 & 29.1 & 30.9 \\
Vegetable oil & 3.5 & 4.2 & 3.2 \\
Fish meal & 2.1 & 5.0 & 0.0 \\
Limestone & 1.8 & 0.9 & 1.43 \\
DCP & 0.9 & 1.2 & 0.9 \\
NaCl & 0.25 & 0.25 & 0.3 \\
Vitamin and mineral Premix ${ }^{\mathrm{a}}$ & 0.5 & 0.5 & 0.5 \\
DL-Methionine & 0.35 & 0.3 & 0.2 \\
L-Lysine HCl & 0.25 & 0.15 & 0.14 \\
L-Threonine & 0.1 & 0.0 & 0.04 \\
Nutrient composition & & & \\
Energy, MJ/kg & 12.5 & 13.0 & 13.4 \\
Crude protein \% & 23.1 & 21.3 & 19.3 \\
Crude fibre (\%) & 3.21 & 3.34 & 3.35 \\
Lysine \% & 1.44 & 1.24 & 1.09 \\
Met+Cys \% & 1.07 & 0.95 & 0.86 \\
Calcium \% & 1.05 & 0.9 & 0.85 \\
Available P \% & 0.50 & 0.45 & 0.42
\end{tabular}

${ }^{a}$ Vitamin \& mineral premix supplied (content per $\mathrm{kg}$ ): vitamin A, $1800000 \mathrm{IU}$; vitamin $\mathrm{D}_{3}, 400000 \mathrm{IU}$; vitamin $\mathrm{E}, 3600$ IU; vitamin $\mathrm{K}_{3}, 400 \mathrm{mg}$; thiamine, $360 \mathrm{mg}$; riboflavin, $1320 \mathrm{mg}$; niacin, $6000 \mathrm{mg}$; vitamin $\mathrm{B}_{6}, 600 \mathrm{mg}$; vitamin $\mathrm{B}_{5}$, 2000; vitamin $B_{12}, 3 \mathrm{mg}$; folic acid, $200 \mathrm{mg}$; biotin, $20 \mathrm{mg}$, choline, $80 \mathrm{~g}$; zinc, $17 \mathrm{~g}$; iron, $10 \mathrm{~g}$; copper, $2 \mathrm{~g}$; manganese, $20 \mathrm{~g}$; selenium, $40 \mathrm{mg}$; iodine, $200 \mathrm{mg}$.

The quantification of AFB1 was evaluated by the ELISA test as described by Peltonen et al. (2000). Amounts of $1.5 \mathrm{mg} \mathrm{AFB1} / \mathrm{kg}$ feed were included in the basal diet and if it was lower than $1.5 \mathrm{mg} / \mathrm{kg}$, AFB1 was added. The Iran National Standard Organization recommends $0.02 \mathrm{mg}$ aflatoxin $/ \mathrm{kg}$ for $\mathrm{NC}$ diets.

Body weight (BW) and feed intake (FI) of each bird were recorded biweekly and the feed conversion ratio (FCR) was calculated. Mortality was observed and recorded daily, and birds that had died, were weighed and the FCR calculated by dividing FI by BW of live plus dead birds.

At the $25^{\text {th }}$ day of the experiment, $0.1 \mathrm{~mL}$ of DNCB and PHA was administered to two chicks per cage. One skin area, $10 \mathrm{~cm}^{2}$, was marked in order to administer the DNCB. Skin thickness was assessed before sensitization. The broiler chicks were sensitized with DNCB at a dose of $0.1 \mathrm{~mL}$ per $\mathrm{cm}^{2}$ area. Skin thickness was evaluated at three parts in this area, after 24 and 48 hours. Also, $0.1 \mathrm{~mL}$ PHA $(10 \mathrm{mg} / \mathrm{mL}$ of acetone and olive oil at a ratio of $4: 1$ ) was administered via intradermal injection between the third and fourth digits of the right foot and the area thickness was evaluated by means of a constant tension micrometer 24 and 48 hours after administration (Global Sources, Shanghai, China).

At the $28^{\text {th }}$ day of the experiment, $3 \mathrm{~mL}$ of $5 \%$ suspension of SRBCs was intravenously injected into two birds per replicate. Blood samples were collected seven days after injection. The blood samples were centrifuged at $2200 \mathrm{~g}$ for 12 minutes. The sera were stored at $-20^{\circ} \mathrm{C}$ until analysis. Each serum sample was inactivated at $56{ }^{\circ} \mathrm{C}$ for 30 min and then analyzed for total anti-SRBC antibodies as explained by Delhanty \& Solomon (1996). In summary, each inactivated serum sample was titrated for total and mercaptoethanol (ME)-resistant (IgG) anti-SRBC antibody titers. ME-sensitive (IgM) antibody titers were achieved by subtracting the level (titer) of IgG antibodies from total antibodies. All titer data were reported in terms of $\log 2$.

On day 42, two birds from each replicate were killed. Intestinal segments were separated, $2 \mathrm{~cm}$ of jejunal and ileal samples were preserved in a 10\% formaldehyde phosphate buffer for 48 hours. Subsequently it was embedded in paraffin, fixed on Microtome, sliced to a thickness of $3 \mu \mathrm{m}$, and dehydrated on a hotplate. The sample was put on a glass slide, dyed with hematoxylin and eosin, and 
evaluated using a microscope. The prepared slides $(n=5)$ from the jejunal segments of each broiler chick and five well-oriented villi were measured, placed on slides, and the average of the villi measurements was reported as a mean for each bird. Villus width (VW) was assessed at the base of each villus, villus length (VL) was evaluated from the top of the villus to the villus-crypt junction, and crypt depth (CD) was evaluated from the base of the villus to the sub-mucosa.

On day 42 of the experiment, $2.5 \mathrm{~mL}$ of blood was taken from two birds, each replicate, and centrifuged at $3000 \times g$ for 15 minutes after which serum samples were obtained. The levels of triglyceride, glucose and cholesterol were then measured by commercial kits of Pars Azmun (Tehran-Iran) according to the kit manufacturer's recommendations. Aspartate aminotransferase (AST, EC 2.6.1.1) and alanine aminotransferase (ALT, EC 2.6.1.2) activities were measured using ZellBio ${ }^{\circledR} \mathrm{GmbH}$ commercial kits by the ELISA method, as recommended by the producer company.

The data obtained from the experiment were analysed by applying the ANOVA technique (SAS software) (SAS, 2001). Different group means were compared by Duncan's multiple range tests (DMRT). The level of significance was $P<0.05$ or lower. For antibody titer, the log 2 transformations were done on antibody titers before statistical analysis.

\section{Results}

The effects of AFB1 and dietary inclusion of prebiotics and commercial toxin binders on growth performance are presented in Table 2. As indicated by the results, growth performance was not influenced by experimental treatments during the starter phase $(P>0.05)$. However, the PC group showed higher FCR and lower BW and $\mathrm{FI}$ in comparison with the NC group during grower and finisher periods $(P<0.05)$. Dietary inclusion of prebiotics and commercial toxin binders could significantly alleviate the adverse effects of AFB1 on performance during grower and finisher periods $(P<0.05)$. Dietary inclusion of prebiotics and commercial toxin binders, singly and combined form, increased FI and BW and also decreased FCR in birds fed aflatoxin-contaminated diets $(P<0.05)$. There were no significant differences among the prebiotic and

Table 2 Effects of dietary inclusion of commercial toxin binders and prebiotics on feed intake, body weight and the feed conversion ratio of broiler chicks receiving aflatoxin-contaminated and basal diets containing commercial toxin binders and prebiotics

\begin{tabular}{|c|c|c|c|c|c|c|c|c|c|}
\hline \multirow[b]{2}{*}{ Days } & \multicolumn{3}{|c|}{ Feed intake (g) } & \multicolumn{3}{|c|}{ Body weight (g) } & \multicolumn{3}{|c|}{ Feed conversion ratio } \\
\hline & $0-10$ & $11-24$ & $25-42$ & $0-10$ & $11-24$ & $25-42$ & $0-10$ & $11-24$ & $25-42$ \\
\hline \multicolumn{10}{|l|}{ Treatments* } \\
\hline NC & 252 & $1180^{\mathrm{a}}$ & $2600^{\mathrm{a}}$ & 258 & $655^{a}$ & $1423^{a}$ & 0.97 & $1.8^{\mathrm{b}}$ & $1.8^{\mathrm{c}}$ \\
\hline PC & 252 & $960^{c}$ & $2380^{c}$ & 266 & $481^{c}$ & $1056^{\mathrm{c}}$ & 0.98 & $2.0^{\mathrm{a}}$ & $2.1^{\mathrm{a}}$ \\
\hline NC+ASRI1 & 250 & $1160^{\mathrm{a}}$ & $2690^{\mathrm{a}}$ & 252 & $645^{\mathrm{a}}$ & $1492^{\mathrm{a}}$ & 0.99 & $1.8^{\mathrm{b}}$ & $1.8^{\mathrm{c}}$ \\
\hline $\mathrm{NC}+\mathrm{ASRI2}$ & 254 & $1175^{\mathrm{a}}$ & $2655^{a}$ & 250 & $647^{a}$ & $1475^{\mathrm{a}}$ & 1.0 & $1.8^{\mathrm{b}}$ & $1.8^{\mathrm{c}}$ \\
\hline NC+Pre & 251 & $1183^{\mathrm{a}}$ & $2640^{\mathrm{a}}$ & 249 & $638^{a}$ & $1448^{a}$ & 1.0 & $1.9^{b}$ & $1.8^{\mathrm{C}}$ \\
\hline PC+ASRI1 & 253 & $1052^{b}$ & $2440^{b}$ & 259 & $590^{b}$ & $1295^{\mathrm{b}}$ & 0.98 & $1.8^{\mathrm{b}}$ & $1.9^{b}$ \\
\hline$P C+A S R I 2$ & 260 & $1045^{\mathrm{b}}$ & $2460^{b}$ & 252 & $589^{b}$ & $1273^{b}$ & 1.0 & $1.8^{\mathrm{b}}$ & $1.9^{\mathrm{b}}$ \\
\hline PC+Pre & 251 & $1045^{\mathrm{b}}$ & $2460^{b}$ & 249 & $579^{b}$ & $1273^{b}$ & 1.0 & $1.8^{\mathrm{b}}$ & $1.9^{b}$ \\
\hline PC+Pre+ASRI1 & 254 & $1077^{\mathrm{b}}$ & $2460^{b}$ & 248 & $591^{b}$ & $1296^{b}$ & 1.0 & $1.8^{\mathrm{b}}$ & $1.9^{b}$ \\
\hline PC+Pre+ASRI2 & 257 & $1079^{b}$ & $2470^{b}$ & 247 & $581^{b}$ & $1301^{b}$ & 1.0 & $1.8^{\mathrm{b}}$ & $1.9^{b}$ \\
\hline$P$-value & 0.47 & 0.02 & 0.02 & 0.7 & 0.02 & 0.01 & 0.1 & 0.03 & 0.03 \\
\hline SEM & 2.61 & 20.15 & 18.2 & 4.52 & 15.2 & 30.1 & 0.2 & 0.04 & 0.02 \\
\hline
\end{tabular}

* Non aflatoxin contaminated diet (NC), aflatoxin-contaminated diet (PC), NC diet containing ASRI1 toxin binder (NC+ASRI1), NC diet containing ASRI2 toxin binder (NC+ASRI2), aflatoxin-contaminated diet containing prebiotics (NC+Pre), PC diet containing ASRI1 toxin binder (PC+ASRI1), PC diet containing ASRI2 toxin binder (PC+ASRI2), aflatoxin-contaminated diet containing probiotics (PC+Pre), $P C$ diet containing prebiotics+ASRI1 toxin binder (PC+Pre+ASRI1), PC diet containing ASRI2 toxin binder+prebiotics (PC+Pre+ASRI2)

Superscripts $(\mathrm{a}-\mathrm{d})$ show significant differences $(P<0.05)$ in each column 
commercial toxin binder groups, singly or combined, in both non-aflatoxin and aflatoxin-contaminated diets during the grower and finisher periods $(P>0.05)$. The addition of prebiotics and commercial toxin binders to the diet did not alter performance, compared to the NC group with nonaflatoxin diets.

The effects of commercial toxin binders and prebiotics on humoral and cellular immunities are presented in Table 3. The lower antibody titer against SRBC and PHA and DNCB after 24 and 48 hours was observed in the PC group, compared to the NC group $(P<0.05)$. However, the inclusion of commercial toxin binders and prebiotics to the diet could increase cellular and humoral immunities, compared to the PC group $(P<0.05)$. Dietary inclusion of commercial toxin binders and prebiotics had similar effects on cellular and humoral immunities $(P>0.05)$. However, adding commercial toxin binders and prebiotics to non-aflatoxin diets would not have had a more beneficial effect in comparison with the NC group $(P>0.05)$.

Table 3 Effects of dietary inclusion of commercial toxin binders and prebiotics on antibody titer against SRBC and response to PHA and DNCB after $24 \mathrm{~h}$ and $48 \mathrm{~h}$ in broiler chicks fed with aflatoxin-contaminated and basal diets

\begin{tabular}{lcccccc}
\hline Treatments $^{*}$ & IgG & IgM & PHA-24 & PHA-48 & DNCB-24 & DNCB-48 \\
\hline NC & $3.40^{\mathrm{a}}$ & $1.95^{\mathrm{a}}$ & $0.79^{\mathrm{a}}$ & $0.44^{\mathrm{a}}$ & $0.73^{\mathrm{a}}$ & $0.52^{\mathrm{a}}$ \\
PC & $2.75^{\mathrm{c}}$ & $1.60^{\mathrm{c}}$ & $0.58^{\mathrm{c}}$ & $0.36^{\mathrm{c}}$ & $0.41^{\mathrm{c}}$ & $0.39^{\mathrm{c}}$ \\
NC+ASRI1 & $3.35^{\mathrm{a}}$ & $1.95^{\mathrm{a}}$ & $0.76^{\mathrm{a}}$ & $0.43^{\mathrm{a}}$ & $0.71^{\mathrm{a}}$ & $0.54^{\mathrm{a}}$ \\
NC+ASRI2 & $3.29^{\mathrm{a}}$ & $1.99^{\mathrm{a}}$ & $0.75^{\mathrm{a}}$ & $0.43^{\mathrm{a}}$ & $0.72^{\mathrm{a}}$ & $0.51^{\mathrm{a}}$ \\
NC+Pre & $3.31^{\mathrm{a}}$ & $1.95^{\mathrm{a}}$ & $0.76^{\mathrm{a}}$ & $0.43^{\mathrm{a}}$ & $0.71^{\mathrm{a}}$ & $0.52^{\mathrm{a}}$ \\
PC+ASRI1 & $3.10^{\mathrm{b}}$ & $1.55^{\mathrm{b}}$ & $0.61^{\mathrm{b}}$ & $0.39^{\mathrm{b}}$ & $0.56^{\mathrm{b}}$ & $0.48^{\mathrm{b}}$ \\
PC+ASRI2 & $3.15^{\mathrm{b}}$ & $1.57^{\mathrm{b}}$ & $0.62^{\mathrm{b}}$ & $0.39^{\mathrm{b}}$ & $0.57^{\mathrm{b}}$ & $0.48^{\mathrm{b}}$ \\
PC+Pre & $3.16^{\mathrm{b}}$ & $1.54^{\mathrm{b}}$ & $0.62^{\mathrm{b}}$ & $0.39^{\mathrm{b}}$ & $0.57^{\mathrm{b}}$ & $0.48^{\mathrm{b}}$ \\
PC+Pre+ASRI1 & $3.13^{\mathrm{b}}$ & $1.59^{\mathrm{b}}$ & $0.62^{\mathrm{b}}$ & $0.39^{\mathrm{b}}$ & $0.57^{\mathrm{b}}$ & $0.48^{\mathrm{b}}$ \\
PC+Pre+ASRI2 & $3.17^{\mathrm{b}}$ & $1.56^{\mathrm{b}}$ & $0.62^{\mathrm{b}}$ & $0.39^{\mathrm{b}}$ & $0.57^{\mathrm{b}}$ & $0.48^{\mathrm{b}}$ \\
P-value & 0.031 & 0.03 & 0.03 & 0.03 & 0.01 & 0.02 \\
SEM & 0.12 & 0.05 & 0.05 & 0.02 & 0.02 & 0.01 \\
& & & & & & \\
\hline
\end{tabular}

\footnotetext{
* Non aflatoxin contaminated diet (NC), aflatoxin-contaminated diet (PC), NC diet containing ASRI1 toxin binder (NC+ASRI1), NC diet containing ASRI2 toxin binder (NC+ASRI2), aflatoxin-contaminated diet containing prebiotics (NC+Pre), PC diet containing ASRI1 toxin binder (PC+ASRI1), PC diet containing ASRI2 toxin binder (PC+ASRI2), aflatoxin-contaminated diet containing probiotics (PC+Pre), PC diet containing prebiotics+ASRI1 toxin binder (PC+Pre+ASRI1), PC diet containing ASRI2 toxin binder+ prebiotics (PC+Pre+ASRI2)

Superscripts $(\mathrm{a}-\mathrm{C})$ show significant differences $(P<0.05)$ in each column
}

Similar to previous findings, the PC groups showed lower VL, VW and CD compared to the NC group (Table 4). However, dietary supplementation of commercial toxin binders and prebiotics alleviated any negative effects of aflatoxin on the mentioned parameters $(P<0.05)$. In the NC-based diets, additives did not improve jejunal morphology in comparison with the NC group $(P<0.05)$.

The PC group showed lower serum concentrations of triglycerides, cholesterol and glucose, and higher serum AST and ALT activities compared to the NC group $(P<0.05$; Table 5$)$. However, no significant differences were found among groups containing additives, compared to the NC group, as regards the serum concentrations of triglycerides, cholesterol and glucose $(P>0.05)$, indicating that dietary inclusion of prebiotics and commercial toxin binders could alleviate the adverse effects of aflatoxin on these blood parameters. A combination of prebiotics and toxin binders could significantly reduce the adverse effects of aflatoxin on liver enzymes $(P<0.05)$. However, prebiotics and toxin binders in single form also showed lower serum activities of liver enzymes, compared to the PC group $(P<0.05)$. 
Table 4 Effects of dietary inclusion of commercial toxin binders and prebiotics on villus length, villus width and crypt depth of jejunum of broiler chicks fed the contaminated and basal diets

\begin{tabular}{lccc}
\hline Treatments $^{*}$ & $\begin{array}{c}\text { Villus length } \\
(\boldsymbol{\mu m})\end{array}$ & $\begin{array}{c}\text { Villus width } \\
(\boldsymbol{\mu} \mathrm{m})\end{array}$ & $\begin{array}{c}\text { Crypt depth } \\
(\boldsymbol{\mu m})\end{array}$ \\
\hline NC & $1980^{\mathrm{a}}$ & $216.7^{\mathrm{a}}$ & $179.2^{\mathrm{a}}$ \\
PC & $1484^{\mathrm{c}}$ & $189.8^{\mathrm{c}}$ & $138.4^{\mathrm{c}}$ \\
NC+ASRI1 & $1952^{\mathrm{a}}$ & $238.0^{\mathrm{a}}$ & $174.4^{\mathrm{a}}$ \\
NC+ASRI2 & $1944^{\mathrm{a}}$ & $232.2^{\mathrm{a}}$ & $175.8^{\mathrm{a}}$ \\
NC+Pre & $1926^{\mathrm{a}}$ & $231.7^{\mathrm{a}}$ & $178.0^{\mathrm{a}}$ \\
PC+ASRI1 & $1692^{\mathrm{b}}$ & $200.6^{\mathrm{b}}$ & $155.0^{\mathrm{b}}$ \\
PC+ASRI2 & $1687^{\mathrm{b}}$ & $206.5^{\mathrm{b}}$ & $159.2^{\mathrm{b}}$ \\
PC+Pre & $1637^{\mathrm{b}}$ & $205.5^{\mathrm{b}}$ & $152.2^{\mathrm{b}}$ \\
PC+Pre+ASRI1 & $1644^{\mathrm{b}}$ & $204.5^{\mathrm{b}}$ & $157.2^{\mathrm{b}}$ \\
PC+Pre+ASRI2 & $1657^{\mathrm{b}}$ & $203.5^{\mathrm{b}}$ & $156.2^{\mathrm{b}}$ \\
P-value & 0.011 & 0.021 & 0.031 \\
SEM & 20.15 & 12.01 & 3.15 \\
\hline
\end{tabular}

* Non-aflatoxin contaminated diet (NC), aflatoxin-contaminated diet (PC), NC diet containing ASRI1 toxin binder (NC+ASRI1), NC diet containing ASRI2 toxin binder (NC+ASRI2), aflatoxin-contaminated diet containing prebiotics (NC+Pre), PC diet containing ASRI1 toxin binder (PC+ASRI1), PC diet containing ASRI2 toxin binder (PC+ASRI2), aflatoxin-contaminated diet containing probiotics (PC+Pre), PC diet containing prebiotics+ASRI1 toxin binder (PC+Pre+ASRI1), PC diet containing ASRI2 toxin binder+ prebiotics (PC+Pre+ASRI2)

Superscripts $(\mathrm{a}-\mathrm{C})$ show significant differences $(P<0.05)$ in each column

Table 5 Effects of dietary inclusion of commercial toxin binders and prebiotics on serum biochemical parameters in broiler chicks treated with AFB1 and basal diets at 42 days of age

\begin{tabular}{lccccc}
\hline Parameters & Triglyceride & Cholesterol & Glucose & AST & ALT \\
\hline Treatments & $(\mathrm{mg} / \mathrm{dL})$ & $(\mathrm{mg} / \mathrm{dL})$ & $(\mathrm{mg} / \mathrm{dL})$ & $(\mathrm{IU} / \mathrm{L})$ & $(\mathrm{IU} / \mathrm{L})$ \\
NC & $120.7^{\mathrm{a}}$ & $175.5^{\mathrm{a}}$ & $190.5^{\mathrm{a}}$ & $165.5^{\mathrm{d}}$ & $5.1^{\mathrm{d}}$ \\
PC & $110.3^{\mathrm{b}}$ & $145.0^{\mathrm{b}}$ & $160.3^{\mathrm{b}}$ & $250.5^{\mathrm{a}}$ & $8.5^{\mathrm{a}}$ \\
NC+ASRI1 & $120.0^{\mathrm{a}}$ & $177.5^{\mathrm{a}}$ & $187.5^{\mathrm{a}}$ & $170.5^{\mathrm{d}}$ & $5.4^{\mathrm{d}}$ \\
NC+ASRI2 & $117.0^{\mathrm{a}}$ & $173.3^{\mathrm{a}}$ & $191.6^{\mathrm{a}}$ & $167.5^{\mathrm{d}}$ & $5.3^{\mathrm{d}}$ \\
NC+Pre & $119.3^{\mathrm{a}}$ & $178.3^{\mathrm{a}}$ & $191.6^{\mathrm{a}}$ & $174.5^{\mathrm{b}}$ & $5.3^{\mathrm{d}}$ \\
PC+ASRI1 & $119.3^{\mathrm{a}}$ & $179.3^{\mathrm{a}}$ & $189.3^{\mathrm{a}}$ & $199.3^{\mathrm{b}}$ & $7.3^{\mathrm{b}}$ \\
PC+ASRI2 & $115.3^{\mathrm{a}}$ & $179.3^{\mathrm{a}}$ & $189.3^{\mathrm{a}}$ & $199.3^{\mathrm{b}}$ & $7.4^{\mathrm{b}}$ \\
PC+Pre & $115.3^{\mathrm{a}}$ & $179.3^{\mathrm{a}}$ & $189.3^{\mathrm{a}}$ & $199.3^{\mathrm{b}}$ & $7.6^{\mathrm{b}}$ \\
PC+Pre+PASRI1 & $118.0^{\mathrm{a}}$ & $180.0^{\mathrm{a}}$ & $190.0^{\mathrm{a}}$ & $184.5^{\mathrm{c}}$ & $6.1^{\mathrm{c}}$ \\
PC+Pre+ASRI2 & $120.5^{\mathrm{a}}$ & $182.5^{\mathrm{a}}$ & $190.0^{\mathrm{a}}$ & $182.5^{\mathrm{c}}$ & $6.1^{\mathrm{c}}$ \\
P value & 0.032 & 0.001 & 0.001 & $<0.0001$ & $<0.0001$ \\
SEM & 1.501 & 2.501 & 1.581 & 2.101 & 0.231
\end{tabular}

Non aflatoxin contaminated diet (NC), aflatoxin-contaminated diet (PC), NC diet containing ASRI1 toxin binder (NC+ASRI1), NC diet containing ASRI2 toxin binder (NC+ASRI2), aflatoxin-contaminated diet containing prebiotics (NC+Pre), PC diet containing ASRI1 toxin binder (PC+ASRI1), PC diet containing ASRI2 toxin binder (PC+ASRI2), aflatoxin-contaminated diet containing probiotics (PC+Pre), PC diet containing prebiotics+ASRI1 toxin binder (PC+Pre+ASRI1), PC diet containing ASRI2 toxin binder+ prebiotics (PC+Pre+ASRI2)

Superscripts $(a-b)$ show significant differences $(P<0.05)$ in each column AST: aspartate aminotransferase; ALT: alanine aminotransferase 


\section{Discussion}

The addition of aflatoxin to the diet without toxin binders could significantly increase FCR and decrease BW and FI in comparison with uncontaminated diets with aflatoxin in grower and finisher periods. Similarly, previous studies have shown a reduction in performance of broiler chicks receiving the aflatoxincontaminated diets. Raju \& Devegowda (2002) have reported that dietary inclusion of $300 \mathrm{ng} / \mathrm{kg}$ of AFB1 reduced body weight by $21 \%$. Another study has shown a $10 \%$ decrease in weight gain of broiler chicks fed the $0.8 \mathrm{mg} / \mathrm{kg}$ of AFB1 (Tedesco et al., 2004).

Despite reports of the adverse effects of aflatoxin on performance, a study by Agboola et al. (2014) did not report adverse effects of aflatoxin on FCR in starter and grower periods. The reduction in performance during grower and finisher periods shown in previous studies may be associated with disorders such as anorexia, listlessness, compromised general health and the inhibitory effects of AFB1 on protein synthesis and lipogenesis (Kiran et al., 1998) and/or disturbances in macromolecules metabolism (Cheeke \& Shull, 1985). Mahmood et al. (2017) reported that a decrease in BW is due to decreased FI. In this study, food intake was decreased which can influence BW. In addition, Mahmood et al. (2017) showed that aflatoxins produce toxic metabolites in the liver which prevent protein synthesis and thus culminate in anorexia. The decreased protein synthesis can reduce weight gain; however, a decreased feed intake can enhance the negative effects on BW. The decreased BW influences FCR and performance is thus decreased by AFB1.

Dietary inclusion of commercial toxin binders and prebiotics in contaminated diets could improve performance during grower and finisher periods. Commercial toxin binders are included in diets in order to increase the digestion of nutrients by removing toxic metabolites and increasing production of essential pancreatic juices to digestion of available nutrients in diets (Agboola et al., 2014). Similarly, Agboola et al. (2014) has shown that commercial toxin binders could alleviate the adverse effects of aflatoxin on performance. Studies have reported contradictory results as to the effects of prebiotics on performance. Some studies have shown positive effects of prebiotics on the performance of birds (Xu et al., 2004; Chee et al., 2010), while others have not found any positive effects (Baurhoo et al., 2009; Morales-López et al., 2009; Yang et al., 2009; Alzueta et al., 2010). Studies have considered different factors which influence the effects of prebiotics on birds including environment, management, diet composition and characteristics of the birds (Yang et al., 2009). These factors can affect the efficiency of prebiotics on performance. In this study, prebiotics and commercial toxin binders supplemented to uncontaminated diets did not show any improvement, compared to the NC. However, dietary inclusion of prebiotics and commercial toxin binders to contaminated diets did improve performance. It can be argued that commercial toxin binders and prebiotics ensure greater efficiency under abnormal conditions. Studies have suggested several mechanisms for improvement in performance by prebiotics such as the decrease in incidences of disease by preventing gut lining colonization by pathogenic bacteria, the inhibition of proliferation, and a decrease in toxins and intestinal pathogens (Benites et al., 2007). In addition, prebiotics improve performance by increasing VL that enhances absorption, and subsequently the birds' energy and protein efficiency ratio (Salianeh et al., 2011). In this study, VL was increased in the prebiotics group contaminated with aflatoxin, compared to the PC. In summary, binder substances prevent mycotoxin absorption from the gastrointestinal tract and are excreted in the faeces (Gimeno \& Martins, 2011). The effect of synergized interaction among commercial toxin binders and prebiotics on performance was not observed. This may be attributed to the different mechanisms which affect performance. It seems that commercial toxin binders and prebiotics act in different ways and do not give rise to other effects.

The AFB1 decreased immune responses in both humoral and cellular immunity (PC vs NC). AFB1 causes severe hepatoxicity, nephrotoxicity and teratogenicity in birds (Abidin et al., 2016; Kumar et al., 2015). Interdigital administration of PHA could stimulate T-lymphocyte with a slight effect on B-lymphocytes (Raju \& Devegowda, 2002). Birds fed with mycotoxins had lower antibody titers, compared to other birds (Khan et al., 2014). The lower immune responses in AFB1 may be due to the prevention of protein synthesis, which decreases IgG and IgA production (Sur \& Celik, 2004). As expected, prebiotics improve the immune system since they prevent and control growth of Clostridium perfringens and other harmful bacteria (Zakeri et al., 2005). Another mechanism is that prebiotics help the immune system by increasing lactic acid density in the intestine and increasing the activity of lactobacillus and/or macrophages (Kamrani et al., 2012). Commercial toxin binders seem to bind with AFB1 in the intestine and prevent its negative effects on the immune system. However, additives did not improve the immune system in NC-based diets, compared to the NC group. It seems that prebiotics and commercial toxin binders play a particularly positive role under compromised intestinal conditions.

Similar to previous findings, AFB1 had negative effects on jejunal morphology, and the dietary inclusion of commercial toxin binders and prebiotic improved the mentioned parameters. The deeper CD is indexed for fast tissue turnover that allows renewal of the villus as required in response to normal sloughing or inflammation synthesis, pathogens or their toxins, and the high demand for tissue (Yason et al., 1987). 
The reduced villi and deeper crypts may decrease nutrient absorption, elevate secretion in the gastrointestinal tract and lower performance (Xu et al., 2004), indicating that additives can improve morphology and performance in AFB1 groups. Pelicano et al. (2005) reported that pathogens disturb the normal microflora and intestinal epithelium and compromise the ability to digest and absorb nutrients, which would ultimately reduce villus height. As stated before, prebiotics modulate the intestinal system and improve bacterial population, demonstrating that prebiotics may help improve intestinal morphology. Savage (1972) showed that the removal of pathogens from the intestinal tract can provide optimum environmental conditions for digestion, absorption and metabolism of growth-enhancing nutrients which help to improve intestinal morphology. It seems that commercial toxin binders prevent AFB1 absorption in the intestine and help to increase jejunal morphology.

The PC group showed lower serum concentrations of triglycerides, cholesterol and glucose and higher serum activity of AST and ALT enzymes, compared to the NC group. Liver injuries are the most common injuries created by toxicity of aflatoxin, which affect blood parameters. The biochemical alterations during aflatoxicosis can be attributed to liver injuries (Kubena et al., 1993; Shi et al., 2006). Liver injuries are responsible for changes in serum indices (Gholami-Ahangaran et al., 2016). The increased activities of these enzymes in chickens treated with diets contaminated with aflatoxins can be attributed to liver damage and enzyme leakage into the blood vessels (Gholami-Ahangaran et al., 2016). Gowda et al. (2008) also reported that liver damage is responsible in increasing the activities of liver enzymes. Al-Daraji (2012) showed that aflatoxin-contaminated diets had significantly negative effects on lipid profile and glucose concentration. Aflatoxin is a hepatotoxin which causes injuries to the liver and a subsequent decrease in glucose and lipids (Adav \& Godinwar, 1997). In contrast to our findings, Abdel-Fattah \& Fararh (2009) did not observe significant differences in serum AST and ALT activities between birds which received prebiotics and the control group. Prebiotics in combination with commercial toxin binders showed more efficiency, compared to the single form, indicating that both have a synergism interaction effect on liver enzymes. Saadia \& Nagla (2010) illustrated that the supplementation of yeast into the diet significantly improved lipid concentrations. Toxin binder activity of commercial toxin binders in the gut system can be a reason for the improvement of blood biochemical parameters (Haskard et al., 2001). It seems that a combination of prebiotics and commercial toxin binders alleviates the adverse effects of AFB1 on the liver, and subsequently improves blood biochemical parameters.

\section{Conclusion}

This study aimed to investigate the efficiency of toxin binders and prebiotics on the growth and immunity of broiler chicks fed with uncontaminated and AFB1-contaminated diets. Aflatoxin addition to the diet had negative effects on growth performance during grower and finisher periods, immunity, jejunal morphology and blood parameters. However, the addition of commercial toxin binders and prebiotics to the diet could alleviate the negative effects of AFB1 on these parameters. A synergistic interaction effect was not observed among commercial toxin binders and prebiotics, except for liver enzymes. On the basis of our findings, the use of prebiotics in alleviating adverse effects of AFB1, is recommended.

\section{Acknowledgments}

This work was supported by Islamic Azad University (Shabestar-Iran).

\section{Authors'Contributions}

All authors had similar corporation in performing experiment and preparing the manuscript.

\section{Conflict of Interest Declaration}

The authors declare no conflict of interest.

\section{References}

Abdallah, M.F., Girgin, G. \& Baydar, T., 2015. Occurrence, prevention and limitation of mycotoxins in feeds. Anim. Nutr. Feed Technol. 15, 471-490.

Abdel-Fattah, F.A.I. \& Fararh. K.M., 2009. Effect of dietary supplementation of probiotic, prebiotic and synbiotic on performance, carcass characteristics, blood picture and some biochemical parameters in broiler chickens. Benha Vet. Med. J. 20, 9-23.

Abidin, Z., Khan, M.Z. \& Khatoon, A., 2016. Protective effects of L-carnitine upon toxicopathological alterations induced by ochratoxin A in white Leghorn cockerels. Toxin Rev. 35, 157-164.

Adav, S.S. \& Godinwar, S.S., 1997. Effects of aflatoxin B1 on liver microsomal enzymes in different strains of chickens. Comp. Biochem. Physiol. 118, 185-189.

Agboola, A.F., Omidiwura, B.R.O., Odu, O., Odupitan, F.T. \& Iyayi, E.A., 2014. Effect of probiotic and toxin binder on performance, intestinal microbiota and gut morphology in broiler chickens. J. Anim. Sci. Adv. 5, 1369-1379. 
Al-Daraji, H.J., 2012. Effect of liquorice extract supplemented diet on aflatoxin degradation and blood parameters in broiler chickens. Int. J. Pharm. Psychopharmacol. Res. 2, 87-91.

Alzueta, C., Rodríguez, M., Ortiz, L., Rebolé, A. \& Treviño, J., 2010. Effects of inulin on growth performance, nutrient digestibility and metabolisable energy in broiler chickens. Br. Poult. Sci. 51, 393-398.

AOAC, 2005. Official Methods of Analysis, $18^{\text {th }} \mathrm{ed}$. Association of Official Analytical Chemists, Washington, DC.

Banlunara, W., Bintvihok, A. \& Kumagai, S., 2005. Immunohistochemical study of proliferating cell nuclear antigen in duckling liver fed with aflatoxin B1 and esterified glucomannan. Toxicon. 46, 954-957.

Basmacioglu, H., Oguz, H., Ergun, M., Col, R. \& Bardane, Y.O., 2005. Effect of dietary esterified glucomannan on performance, serum biochemistry and hematology in broiler exposed to aflatoxin. Czech J. Anim. Sci. 50, 31-39.

Bauer, E., Williams, B.A. Verstegen, M.W.A. \& Mosenthin, R., 2006. Fermentable carbohydrates: potential dietary modulators of intestinal physiology, microbiology and immunity in pigs. In: Mosenthin, R.J., Zentek, T. \& Zebroska, E. (Eds.), Biology of Growing Animals Series: Biology of Nutrition in Growing Animals. Elsevier Limited, Edinburgh, United Kingdom.

Baurhoo, B., Ferket, P. \& Zhao, X., 2009. Effects of diets containing different concentrations of mannanoligosaccharide or antibiotics on growth performance, intestinal development, cecal and litter microbial populations, and carcass parameters of broilers. Poult. Sci. 88, 2262-2272.

Benites, V., Gilharry, R., Gernat, A.G. \& Murillo, J.G., 2007. Effect of dietary mannan oligosaccharide from Bio-Mos or SAF-Mannan on live performance of broiler chickens. J. Appl. Poult. Res. 17, 471-475.

Bhatti, S.A., Khan, M.Z., Saleemi, M.K. \& Saqib, M., 2016. Aflatoxicosis and ochratoxicosis in broiler chicks and their amelioration with locally available bentonite clay. Pak. Vet. J. 36, 68-72.

Binder, E.M., Tan, L.M. \& Chin, L.J., 2007. Worldwide occurrence of mycotoxins in commodities, feeds and feed ingredients. Anim. Feed Sci. Technol. 137, 265-82.

Chee, S., Iji, P., Choct, M., Mikkelsen, L. \& Kocher, A., 2010. Characterisation and response of intestinal microflora and mucins to manno-oligosaccharide and antibiotic supplementation in broiler chickens. Br. Poult. Sci. 51, 368-380.

Cheeke, P.R. \& Shull, L.R., 1985. Natural Toxicants in Feeds and Poisonous Plants. AVAVanNostrand-Reinold, New York, USA.

Delhanty, J.J. \& Solomon, J.B., 1996. The nature of antibodies to goat erythrocytes in the developing chicken. Immunol. $11,103-113$.

Duarte, E.D. \& Smith, T.K., 2005. Mycotoxin Blue Book. Nottingham Univ. Press. pp. 323-339.

El Miniawy, H.M.F., Ahmed, K.A., El-Sanousi, A.A. \& Khattab, M.M.S., 2014. Effect of aflatoxin induced immunosuppression on pathogenesis of $\mathrm{H}_{9} \mathrm{~N}_{2}$ avian influenza virus. Pak. Vet. J. 34, 2348.

Eralsan, G., Essz, D., Akdogan, M., Sahindokuyucu, F. \& Altrintas, L., 2005. The effects of aflatoxin and sodium bentonite and alone on some blood electrolyte levels in broiler chickens. Turk. Vet. Hayvanclk. Dergisi. 29, 601-605.

Gao, J., Zhang, H.J., Yu, S.H., Wu, S.G., Yoon, I., Quigley, J., Gao, Y.P. \& Qi, G.H., 2008. Effects of yeast culture in broiler diets on performance and immunomodulatory functions. Poult. Sci. 87, 1377-1384.

Gholami-Ahangaran, M., Rangsaz, N. \& Azizi, S., 2016. Evaluation of turmeric (Curcuma longa) effect on biochemical and pathological parameters of liver and kidney in chicken aflatoxicosis. Pharm. Biol. 5, 780-787.

Gibson, G.R. \& Roberfroid, M.B., 1995. Dietary modulation of the human colonic microbiota: Introducing the concepts of prebiotics. J. Nutr. 125, 1401-1412.

Gimeno, A. \& Martins, M.L., 2011. Mycotoxinas y MicotoxicosisenAnimales y Humanos. 3rd ed. Special Nutrients-INC, Miame.

Girish, C.K., Smith, T.K. \& Boermans, H.J., 2008. Effects of feeding blends of grains naturally contaminated with Fusarium mycotoxins on performance, hematology, metabolism, and immunocompetence of turkeys. Poult. Sci. 87, 421-432.

Gowda, N.K.S., Ledoux, D.R., Rottinghaus, G.E., Bermudez, A.J. \& Chen, Y.C., 2008. Efficacy of turmeric (Curcuma longa), containing a known level of curcumin, and a hydrated sodium calcium aluminosilicate to ameliorate the adverse effects of aflatoxin in broiler chicks. Poult. Sci. 87, 1125-1130.

Haskard, C.A., El-Nezami, H.S., Kankaanpää, P.E., Salminen, S. \& Ahokas, J.T., 2001. Surface binding of aflatoxin B by lactic acid bacteria. Appl. Environ. Microbiol. 67, 3086-3091.

Huwig, A., Freimund, S., Kappeli, O. \& Dutler, H., 2001. Mycotoxin detoxification of animal feed by different absorbents. Toxicol. Lett. 122, 179-188.

Kamrani, B., Pourakbari, Y. \& Lotfi, S., 2012. Effect of A-Max, protexin and virginamycine on humoral immune of broiler chickens. Int. J. Agric. Crop Sci. 4, 1329-1332.

Khan, W.A., Khan, M.Z. \& Khan, A., 2014. Potential for amelioration of aflatoxin B1-induced immunotoxic effects in progeny of white leghorn breeder hens co-exposed to vitamin E. J. Immunotoxicol. 11, 116-125.

Khan, A., Aalim, M.M., Khan, M.Z., Saleemi, M.K., He, C., Khatoon, A. \& Gul, S.T., 2017. Amelioration of immunosuppressive effects of aflatoxin and ochratoxin A in White Leghorn layers with distillery yeast sludge. Toxin Rev. 1, 1-7.

Kiran, M.M., Demet, O., Ortatatli, M. \& Oğuz, H., 1998. The preventive effect of polyvinyl-polypyrrolidone on aflatoxicosis in broilers. Avian Pathol. 27, 250-255.

Kubena, L.F., Harvey, R.B., Huff, W.E., Elissald, M.H., Yersin, A.G., Philips, T.D. \& Rottinghaus. G.E., 1993. Efficacy of a hydrated sodium calcium aluminosilicate to reduce the toxicity of aflatoxin and diacetoxyscripenol. Poult. Sci. 72 , 51-59.

Kumar, C.B., Reddy, B.S.V. \& Gloridoss, R.G., 2015. Amelioration of aflatoxicosis through a bio-technologically derived aflatoxin degrading commercial product in broilers. Pak. Vet. J. 35, 217-221. 
Mahmood, S., Younus, M., Aslam, A. \& Anjum, A.A., 2017. Toxicological effects of aflatoxin $B_{1}$ on growth performance, humoral immune response and blood profile of Japanese quail. J. Anim. Plant Sci. 27, 833-840.

Marin, D.E. \& Taranu, I., 2015. Ochratoxin A and its effects on immunity. Toxin Rev. 34, 11-20.

Morales-López, R., Auclair, E., García, F., Esteve-Garcia, E. \& Brufau, J., 2009. Use of yeast cell walls; $\beta-1,3 / 1$, 6-glucans; and mannoproteins in broiler chicken diets. Poult. Sci. 88, 601-607.

Mundi, M., Michelle Mikal, K., Haruna Ahmed, O. \& Razid Sarbini, S., 2017. A review on the effects of prebiotics on cell toxicity and integrity, Int. J. Food. Properties 20, S1045-S1052. DOI: 10.1080/10942912.2017.1326937.

Nemati, Z., Karimi, A. \& Besharati, M., 2015. Effects of aflatoxin B1 and yeast cell wall supplementation on the growth performance of broilers. International Conference on Innovations in Chemical and Agricultural Engineering (ICICAE'2015); 2015 Feb 8-9; Kuala Lumpur (Malaysia). Available at: http://dx.doi.org/10.15242/ IAE.IAE0215414.

Ohimain, E.I. \& Ofongo, R.T.S., 2012. The effect of probiotic and prebiotic feed supplementation on chicken health and gut microflora: A review. Int. J. Anim. Vet. Adv. 4, 135-143.

Pelicano, E.R.L., Souza, P.A., Souza, H.B.A., Figueiredo, D.F., Boiago, M.M., Carvalho, S.R. \& Bordon, V.F., 2005. Intestinal mucosa development in broiler chickens fed natural growth promoters. Rev. Bras. Cienc. Avic. 7, 4-10.

Peltonen, K., El-Nezami, H., Salminen, S. \& Ahokas. J., 2000. Binding of aflatoxin B1 by probiotic bacteria. J. Sci. Food Agric. 80, 1942-1945.

Raju, M.V.L.N. \& Devegowda, G., 2002. Esterifed glucomannan in broiler chicken diets contaminated with aflatoxin, ochratoxin and T-2 toxin: Evaluation of its binding ability (in vitro) and efficacy as immunomodulator. AsianAustral. J. Anim. Sci. 15, 1051-1056.

Rezar, V., Frankič, T., Narat, M., Levart, A. \& Salobir, J., 2007. Dose-dependent effects of T-2 toxin on performance, lipid peroxidation, and genotoxicity in broiler chickens. Poult. Sci. 86, 1155-1160.

Ribeiro, A.M.L., Vogt, L.K., Canal, C.W., Cardoso, M.R.I., Labres, R.V., Streck, A.F. \& Bessa, M.C., 2007. Effects of prebiotics and probiotics on the colonization and immune response of broiler chickens challenged with Salmonella enteritidis. Braz. J. Poult. Sci. 9, 193-200.

Ross 308 Broiler, 2007. Nutrition Specification, June 2007. Ross Breeders Limited, Newbridge, Midlothian, Scotland, UK.

Saadia, M. \& Nagla, K.S., 2010. Effect of probiotic (Saccharomyces cerevisiae) adding to diets on intestinal microflora and performance of Hy-Line layers hens. J. Am. Sci. 6, 159-169.

Saleemi, M.K., Khan, M.Z. \& Khan, A., 2017. Study of fungi and their toxigenic potential isolated from wheat and wheat bran. Toxin Rev. 36, 80-88.

Salianeh, N., Shirzad, M.R. \& Seifi, S., 2011. Performance and antibody response of broiler chickens fed diets containing probiotic and prebiotic. J. Appl. Anim. Res. 39, 65-67.

SAS software, 2001. SAS User's Guide: Statistics, Version 9.2, SAS Institute, North Carolina, USA.

Savage, D.C., 1972. Associations and physiological interactions of indigenous microorganisms and gastrointestinal epithelia. Am. J. Clin. Nutr. 25, 1372-1379.

Shi, Y.H., Xu, Z., Feng, J.L. \&. Wang, C.Z., 2006. Efficacy of modified montmorillonite nanocomposite to reduce the toxicity of aflatoxin in broiler chicks. Anim. Feed Sci. Technol. 129, 138-148.

Steiner, T., 2006. Managing Gut Health: Natural Growth Promoters as a Key to Animal Performance. Nottingham University Press, Nottingham, UK. pp. 323-339.

Sur, E. \& Celik, I., 2004. Effect of aflatoxin B1 on the development of the bursa of Fabricius and blood lymphocyte acid phosphatase of the chicken. Br. Poult. Sci. 44, 558-566.

Tedesco, D., Steidler, S., Galletti, S., Tameni, M., Sonzogni, O. \& Ravarotto, L., 2004. Efficacy of silymarin-phospholipid complex in reducing the toxicity of aflatoxin $\mathrm{B}_{1} \mathrm{n}$ broiler chicks. Poult. Sci. 83, 1839-1843.

Xu, Z., Hu, C., Xia, M., Zhan, X. \& Wang, M., 2004. Effects of dietary fructooligosaccharide on digestive enzyme activities, intestinal microflora and morphology of male broilers. Poult. Sci. 82, 1030-1036.

Yang, Y., Iji, P. \& Choct, M., 2009. Dietary modulation of gut microflora in broiler chickens: a review of the role of six kinds of alternatives to in-feed antibiotics. World's Poult. Sci. J. 65, 97-114.

Yason, C.V., Summers, B.A. \& Schat, K.A., 1987. Pathogenesis of rotavirus infection in various age groups of chickens and turkeys: Pathology. Am. J. Vet. Res. 6, 927-938.

Zakeri, A., BozorgmehriFard, M.H.V. \& Feizi, A., 2005. Effectiveness of 3-nitro 4-hydroxy phenyl arsenic acid on growthproduction prameters and effectiveness of coccidioacetat. Iranian J. Vet. Sci. 2 (1), 23-28. 